\title{
ETH ZURIQUE NA FAUUSP
}

\author{
Catherine Otondo
}

(1) Paulo Mendes da Rocha - Bauten und projekte. Zurique: Editora Niggli, 2002.
Figura 1: Fotos do arquivo da autora
Entre os dias 11 e 22 de agosto de 2008, realizou-se o primeiro workshop da ETH Zurique (Instituto Federal de Tecnologia da Suíça) na FAUUSP. A idéia desse intercâmbio partiu da professora Annette Spiro, catedrática da disciplina de Construção do Departamento de Arquitetura da ETH, desde o ano passado.

Ao assumir a cátedra, Annette teve como meta fortalecer a relação entre as duas escolas, pelo intercâmbio de alunos. Sua relação como nossa arquitetura ocorreu com os anos, em inúmeras visitas ao país e na elaboração de um livro sobre a obra de Paulo Mendes da Rocha ${ }^{1}$, e reforçou-se, nos últimos tempos, com a visita do arquiteto Paulo Mendes da Rocha à escola (2006), com a exposição Coletivo (2007), de Oscar Niemeyer, seguida da palestra do professor Rodrigo Queiroz (2007) e com a participação do professor Milton Braga em um seminário de conclusão de curso em julho passado.

A organização do evento foi realizada pelos professores suíços: Rainer Hehl e Udo Thoennissen, ambos do Departamento de Projeto da ETH Zurique, e pelos professores da FAU: Milton Braga e Rodrigo Queiroz, do Departamento de Projeto. As atividades se concentraram em dois âmbitos: a elaboração do projeto de um edifício público no centro da cidade e uma série de palestras.

O desenvolvimento do projeto aconteceu dentro da disciplina AUP-179 (Projetos Normativos), ministrada pelo professor Antonio Carlos Barossi, na qual tanto os estudantes brasileiros como os suíços teriam o mesmo terreno como base. Por conta das diferenças de calendário entre as duas escolas não foi possível realizar equipes mistas entre os alunos, mas as discussões sobre o andamento dos projetos ocorreram conjuntamente.

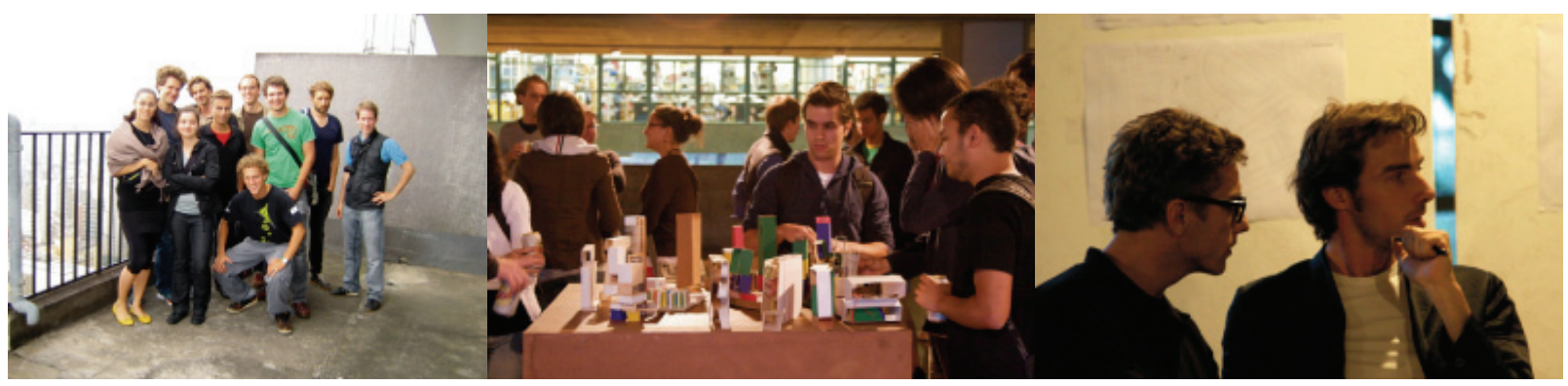


As palestras constituíram parte importante das atividades, pois nelas se pode aprofundar as discussões que estavam sendo levantadas em sala de aula. A primeira foi proferida pelo professor Rainer, sobre o vazio programático como espaço da confrontação das utopias coletivas. Em seguida, Annette Spiro falou sobre a estrutura do curso em sua escola, descrevendo que a disciplina de projeto possui duas formas complementares de abordagem: uma analítica, desenvolvida na disciplina que eles chamam de Entwurf (cuja tradução direta seria design, porém em alemão tem mais o significado de formatação de idéias), na qual os alunos possuem uma relação mais especulativa com o projeto e uma abordagem experimental realizada na disciplina de construção. No mesmo dia Paulo Mendes da Rocha falou aos alunos sobre os desafios de projetar-se para uma cidade como a nossa e a construção de uma nova geografia sobre a cidade preexistente. Na semana seguinte, o professor Ângelo Bucci expôs diversas hipóteses de projeto em São Paulo, baseadas nas idéias desenvolvidas em sua tese de doutorado: Mirar, transpor, invadir, e infiltrar. 0 professor Udo Thoennissen apresentou a palestra "Estrutura versus estrutura" que versava sobre a relação entre as estruturas físicas (aquelas a conferiram resistência ao edifício) e os espaços estruturadores do projeto de arquitetura, e, finalmente, a professora Sophia da Silva Telles expôs as problemáticas enfrentadas (ou não), na arquitetura brasileira, a fim de proporcionar aos alunos suíços uma visão crítica de nossa história. Todas as conferências foram registradas em vídeo e, futuramente, estarão disponibilizadas em DVD na biblioteca da FAUUSP.

Segundo os professores suiços, a importância desse tipo de atividade para seus alunos vai além da tarefa projetual, porque estar em São Paulo, em um ambiente totalmente diferente de Zurique, obriga os estudantes a reconstruir suas premissas de trabalho, enfrentando uma situação desconhecida da qual eles não dispôem de muitas referências para projetar. Um aspecto que chamou a atenção, por exemplo, é a forma coletiva como se trabalha na FAU - os projetos são realizados em grupo, o que não ocorre na $\mathrm{ETH}$, na qual os alunos trabalham individualmente, e em suas casas; assim, esse ambiente de discussão permanente que se dá nos meandros de nossas salas de aula, nas rampas, no café e nos corredores, para eles foi uma prazerosa novidade.

O terreno escolhido para o projeto fica na avenida Consolação, na quadra do Edifico Copan. O programa proposto era de um edifício de serviços públicos, no qual questões como limite entre o público e privado, como ocupar vazios urbanos, mobilidade, deveriam ser destacadas.

A apresentação final dos projetos aconteceu no museu e contou com a participação de vários alunos da FAUUSP e dos professores Ângelo Bucci e Sophia Telles. Foram apresentados três projetos, um por equipe (Ver imagens a seguir). Nas três propostas, pode-se constatar que, em curto período de tempo, os alunos foram capazes de fazer uma leitura do contexto urbano, levantar questões reais de intervenção e, até no caso de uma equipe, assimilar, mesmo de maneira "caricata", formas arquitetônicas locais. 
Trabalho final

Equipe A: Andréas, Christoph, Hannes

$\frac{224}{\dot{n}}$
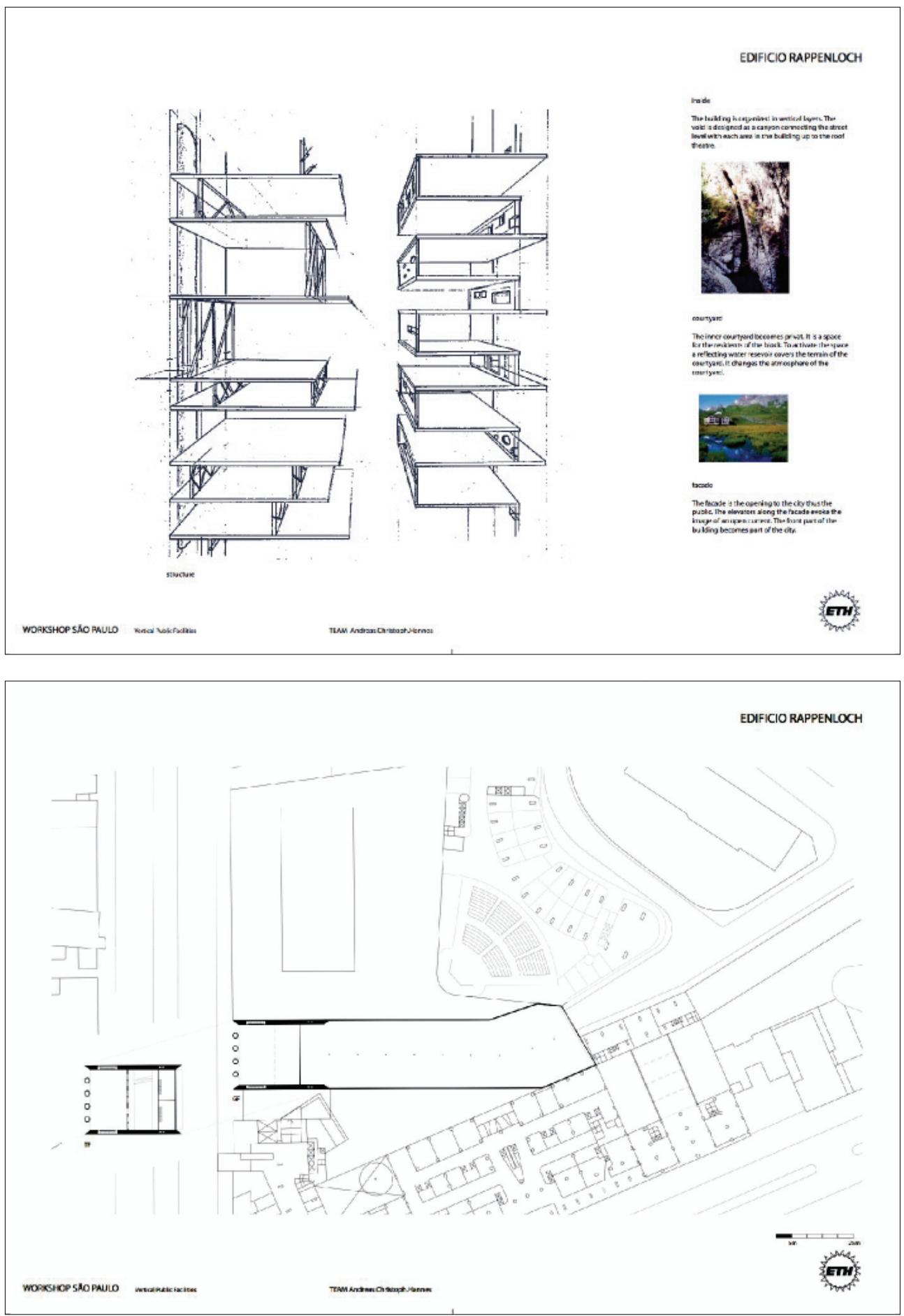


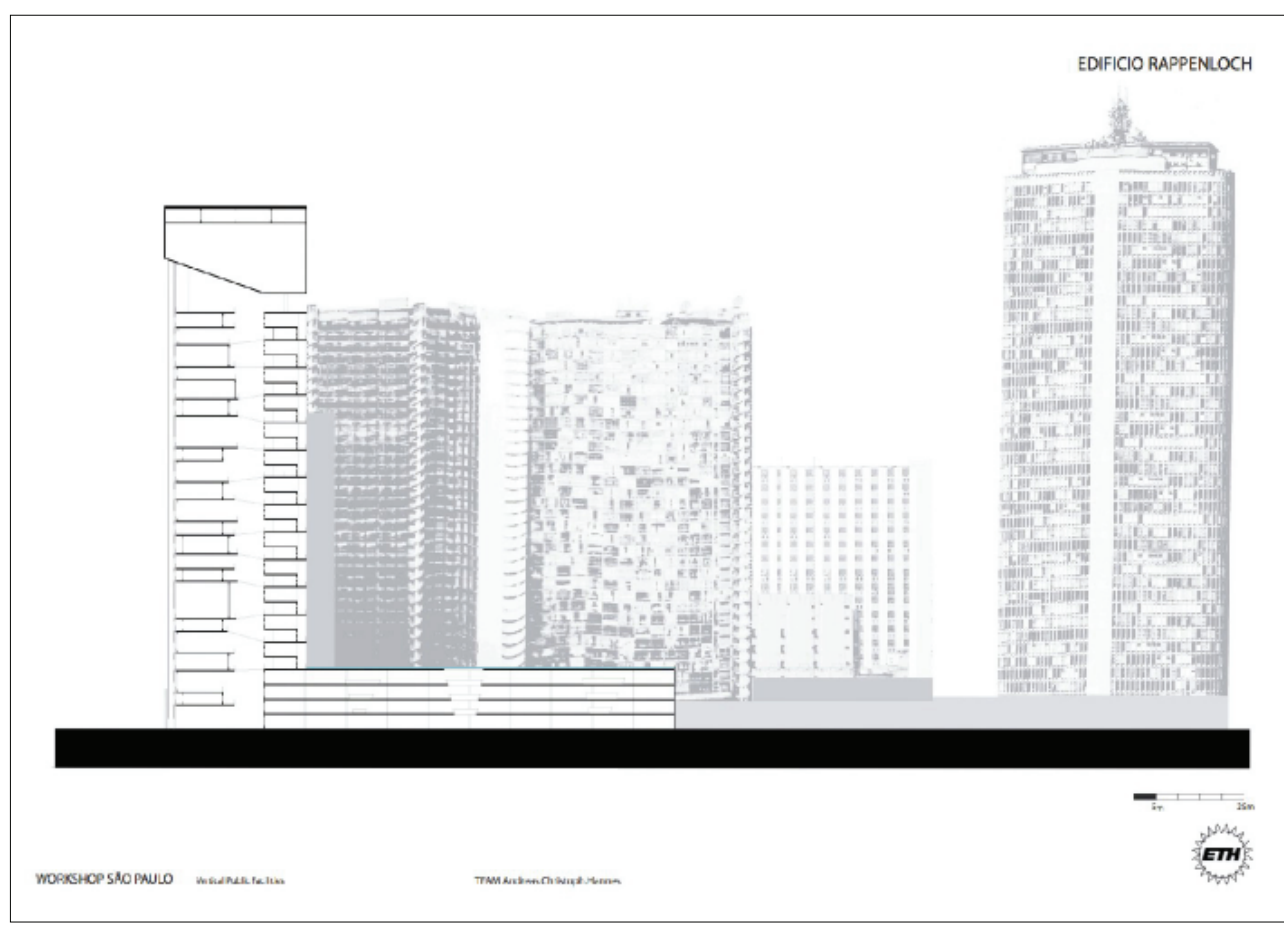

pós- $\mid \stackrel{N}{N}$

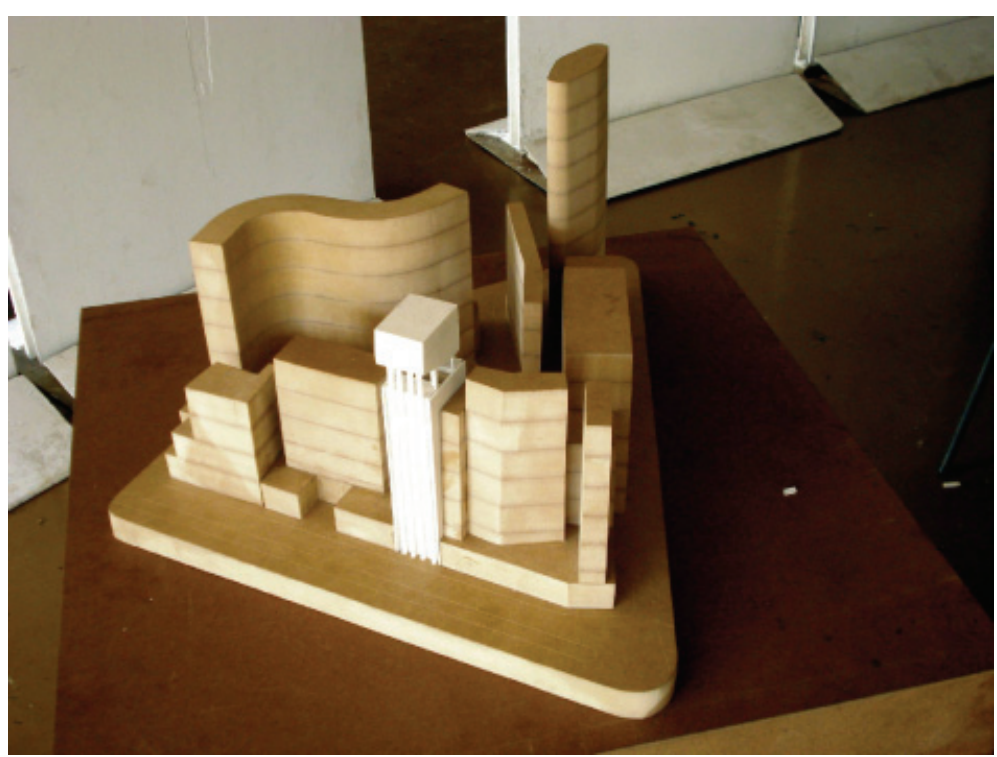


Trabalho final

Equipe B: Olívia Künzil, Philipp Urech, Matina Vogel

๕
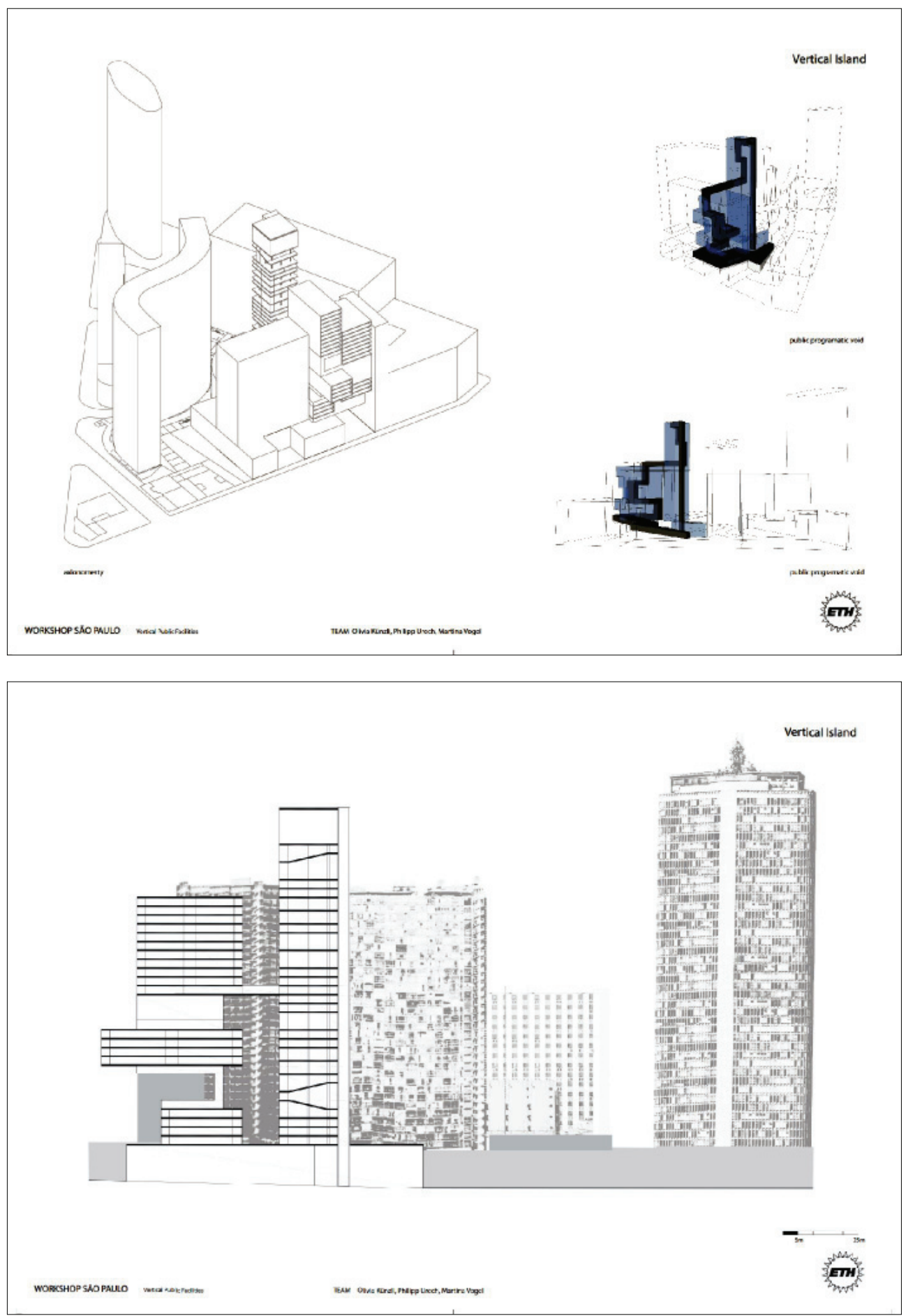


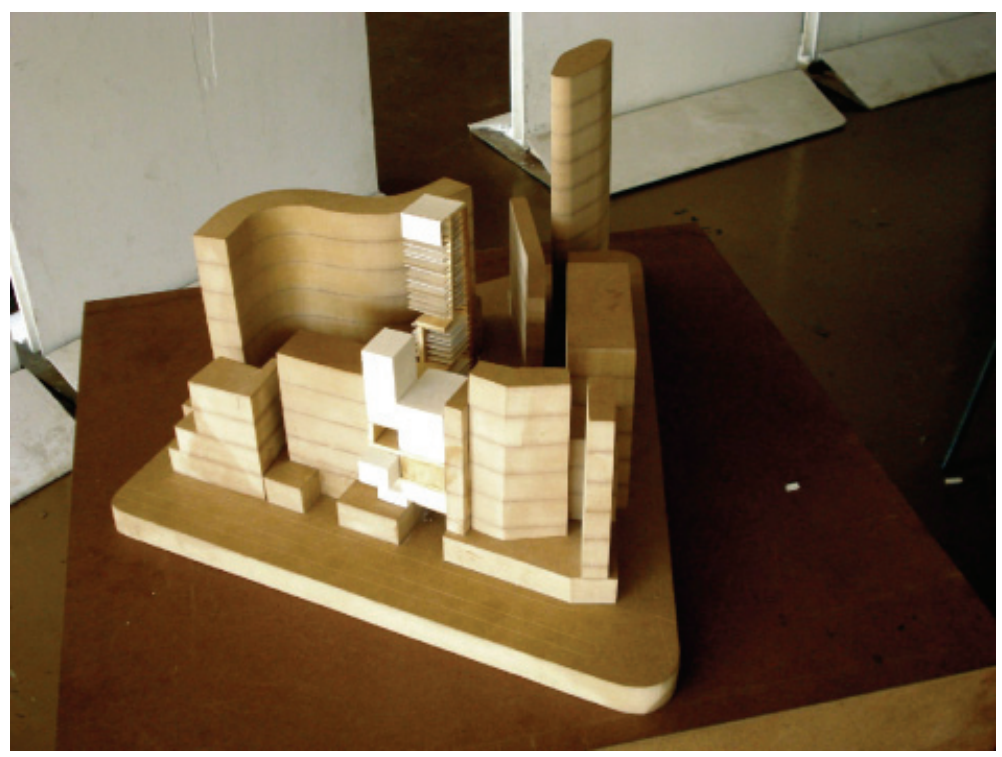

pós- $\mid \frac{N}{N}$ 
Trabalho final

Equipe C: Fabio Don, Philippe Jorish, John Lemmenmeier
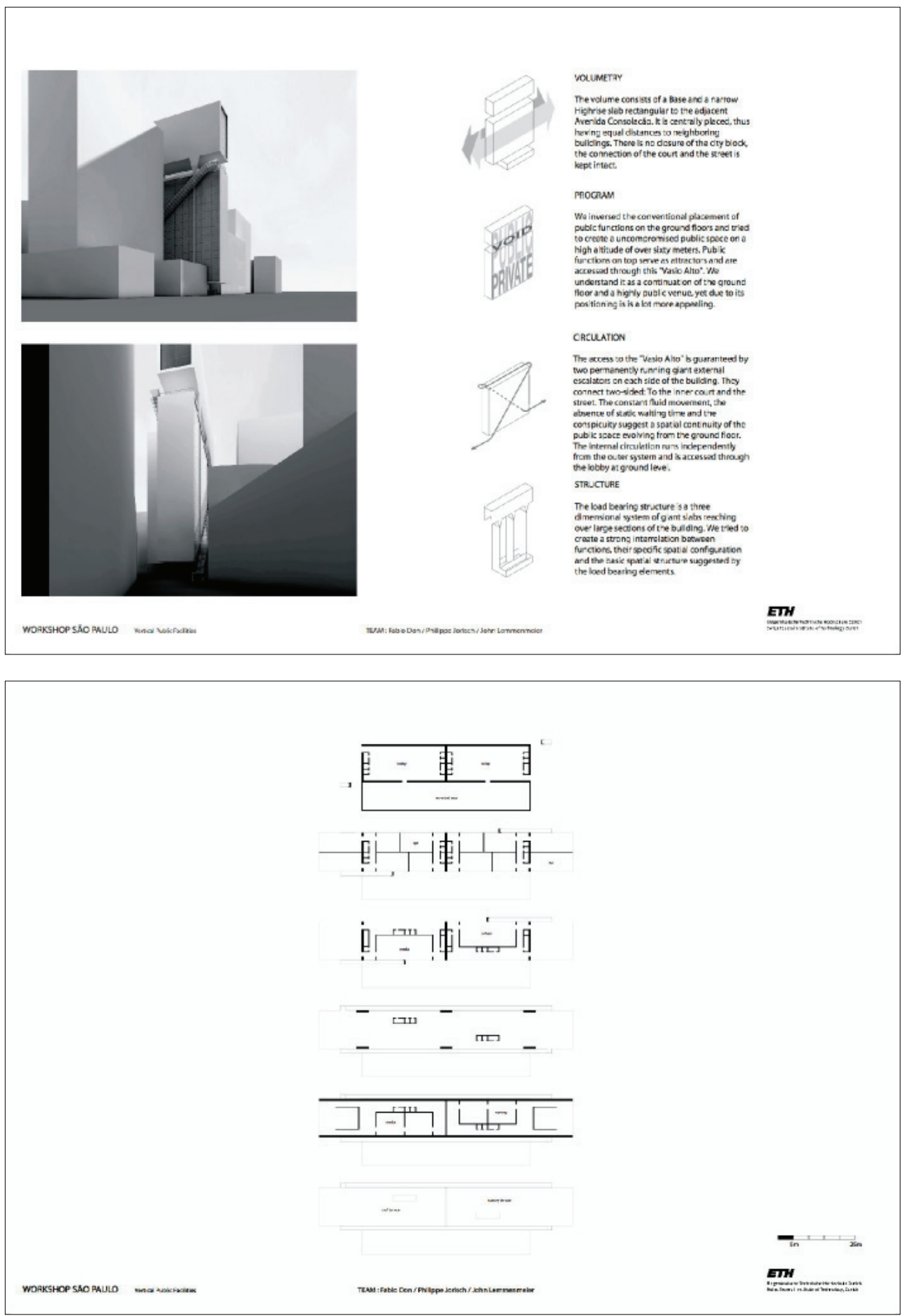


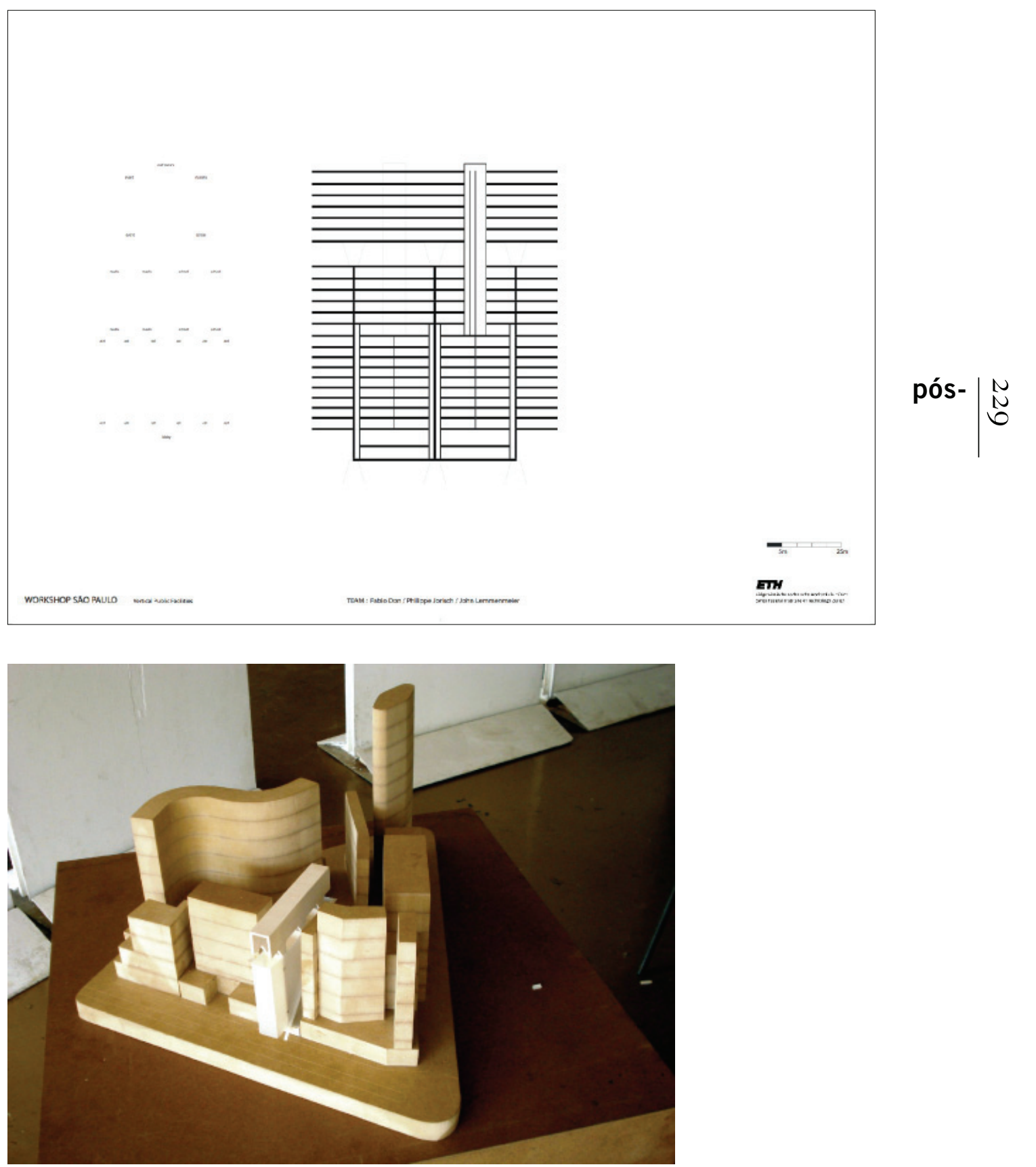


Pelo resultado apresentado pelas equipes e pelas discussões levantadas nas palestras, vimos que esse tipo de intercâmbio deve fazer parte de forma mais rotineira de nosso cotidiano na escola. Para nossos alunos brasileiros, a vinda do grupo suíço fez com que eles refletissem sobre as características de nossa cidade, ao responder às inúmeras questões levantadas pelos alunos estrangeiros e também que estivessem outras maneiras de abordar-se uma questão urbana, com outros procedimentos projetuais, outras premissas atentos para um olhar saudavelmente diferente.

\section{Catherine Otondo}

Arquiteta formada pela FAUUSP em 1993 e aluna de pós-graduação da mesma Universidade, com projeto de pesquisa sob orientação da Profa. Dra. Ana Maria Belluzzo, do Departamento de História da Arquitetura e Estética do Projeto. 